\title{
Cost Analysis of MRI Services in Iran: An Application of Activity Based Costing Technique
}

\author{
Mohsen Bayati ${ }^{1,2}$; Alireza Mahboub Ahari ${ }^{1,3}$; Abbas Badakhshan ${ }^{1}$; Mahin Gholipour ${ }^{4,}$; \\ Hassan Joulaei $^{2}$ \\ ${ }^{1}$ Department of Health Management and Economics, School of Public Health, Tehran University of Medical Sciences, Tehran, Iran \\ ${ }_{3}^{2}$ Health Policy Research Center, Shiraz University of Medical Sciences, Shiraz, Iran \\ 3 Iranian Center of Excellence in Healthcare Management, Tabriz University of Medical Sciences, Tabriz, Iran \\ ${ }^{4}$ Department of Community Medicine, Golestan University of Medical Sciences, Gorgan, Iran \\ *Corresponding author: Mahin Gholipour, Department of Community Medicine, Golestan University of Medical Sciences, Gorgan, Iran. Tel: +98-2165324531, Fax: +98-2188989129, \\ E-mail:dr_gholipour@yahoo.com
}

Received: February 20, 2014; Revised: March 27, 2014; Accepted: April 9, 2014

\begin{abstract}
Background: Considerable development of MRI technology in diagnostic imaging, high cost of MRI technology and controversial issues concerning official charges (tariffs) have been the main motivations to define and implement this study.

Objectives: The present study aimed to calculate the unit-cost of MRI services using activity-based costing (ABC) as a modern cost accounting system and to fairly compare calculated unit-costs with official charges (tariffs).

Materials and Methods: We included both direct and indirect costs of MRI services delivered in fiscal year 2011 in Shiraz Shahid Faghihi hospital. Direct allocation method was used for distribution of overhead costs. We used micro-costing approach to calculate unit-cost of all different MRI services. Clinical cost data were retrieved from the hospital registering system. Straight-line method was used for depreciation cost estimation. To cope with uncertainty and to increase the robustness of study results, unit costs of 33 MRI services was calculated in terms of two scenarios.

Results: Total annual cost of MRI activity center (AC) was calculated at USD 400,746 and USD 532,104 based on first and second scenarios, respectively. Ten percent of the total cost was allocated from supportive departments. The annual variable costs of MRI center were calculated at USD 295,904. Capital costs measured at USD 104,842 and USD 236, 200 resulted from the first and second scenario, respectively. Existing tariffs for more than half of MRI services were above the calculated costs.

Conclusion: As a public hospital, there are considerable limitations in both financial and administrative databases of Shahid Faghihi hospital. Labor cost has the greatest share of total annual cost of Shahid Faghihi hospital. The gap between unit costs and tariffs implies that the claim for extra budget from health providers may not be relevant for all services delivered by the studied MRI center. With some adjustments, $\mathrm{ABC}$ could be implemented in MRI centers. With the settlement of a reliable cost accounting system such as ABC technique, hospitals would be able to generate robust evidences for financial management of their overhead, intermediate and final ACs.
\end{abstract}

Keywords: Health-Care; Magnetic Resonance Imaging; Health Economics; Cost Analysis; Pricing Medical Fees

\section{Background}

Most countries have been buckling under the steeply rising health expenditures. Several reasons seem to be of great importance such as technological advances, population aging, excessive health insurance coverage, and economic fluctuations (1). Iran's medical device market has been suffering from the pressure of importation, especially in diagnostic technologies (2). In a competitive market and increasing budget deficits of governments, health service organizations expose to the challenge of cost containment strategies in general and measuring their costs in particular $(3,4)$. Considering the unpredictable nature of demand for health services, and ethical criticism relating to profit maximization policies, cost containment seems to be an inevitable component of health-care management strategies.

The controversies among insurance companies, healthcare providers and policy makers on current tariffs efficacy, sound to remain questionable. The reason returns to the absence of a reliable, scientific tariff setting mechanism. It has been pointed that up to now, the current system of tariffs setting could not satisfy health system's stakeholders.

Unit-cost of health services is the cornerstone of privatization policies, tariff setting, financial management, and health economic studies (5). One of the most important

Copyright (C) 2015, Tehran University of Medical Sciences and Iranian Society of Radiology. This is an open-access article distributed under the terms of the Creative Commons Attribution-NonCommercial 4.0 International License (http://creativecommons.org/licenses/by-nc/4.0/) which permits copy and redistribute the material just in noncommercial usages, provided the original work is properly cited. 
challenges for hospitals is the lack of accurate, on-time and user-friendly databases in both financial and administrative fields. Considering the above problems, a reliable cost accounting system in accordance with Iranian hospitals seems to be crucial (6).

Activity-based costing (ABC) is an accounting system developed for cost analysis of both product and service organizations (7). This method was developed in the late 1980s in the United States. In the mid 1990s, hospitals began to use this method with the purpose of cost management and calculation of their services (4). ABC is an accounting technique that allows organizations to identify the real costs of their services, in terms of the relevant resource consumed (1, 8-10). Unlike traditional costing methods, $\mathrm{ABC}$ focuses on activity level data instead of exclusive focus on outputs. It is a model of cost management in which not only unit costs could be calculated, but also all procedures would be examined in detail (4). $\mathrm{ABC}$ can potentially improve resource management and consequently increase the efficiency of health service organizations through focusing on value adding interventions (8-11).

Little is known about the implementation of $\mathrm{ABC}$ system in diagnostic procedures. Several studies have been developed in health areas. Kuchta and Zabek (12) applied a model of activity-based cost accounting to determine the cost of a primary health-care center. Both direct and indirect costs of various activities have been retrieved for admission, clinical examination, laboratory and diagnostic tests. As the final result, the unit cost of services was calculated.

Grandlich et al. (3) concluded that the implemented modern costing system for a knee replacement center saved USD 827.62 per surgery. Saber Mahani et al. (6) calculated the unit-cost of radiology services in a teaching hospital. Using an $A B C$ method, authors reported that personnel costs accounted for 55 percent of the total cost of the radiology center. Direct costs involved more than 97 percent of the total costs.

Despite the great attention of the Iranian health sector on healthcare costing, in the recent decade, costing studies that were performed in diagnostic centers have had serious limitations. Although ABC method has been frequently used in the literature, unfortunately, the top-down approach has been employed because of complexity of services. The process of cost analysis in supportive centers was unclear. The majority of the studies reported the average cost of procedures neglecting the fact that different imaging procedures have their own specific condition and consume different resources. The unit-cost produced by the studies might not be able to reflect the differences between real costs and official tariffs.

\section{Objectives}

As the first objective, the present study aimed to devel- op a rigorous methodology for cost accounting of diagnostic procedures delivered in an MRI center. The importance of cost containment strategies in radiology wards, particularly in MRI raises from the fact that based on the hospital's perspective, diagnostic procedures are able to add considerable value to hospital's total revenues and from the health system's perspective, diagnostic imaging can benefit the whole society through recognizing a wide variety of diseases in primary stages. Cost analysis as the backbone of all financial practices would provide useful inputs for healthcare providers. As the second objective, we decided to calculate unit-cost of all MRI services in order to point out the gap between official tariffs and the real cost of these services.

\section{Materials and Methods}

In order to calculate the unit cost of MRI services, we employed ABC method. MRI imaging services delivered in Shahid Faghihi public hospital in fiscal year 2011 were considered as the final cost object. It means that all direct and indirect costs were navigated to these services. All clinical and financial data were investigated from the hospital perspective as a public health provider. Data gathering phase was done through a review of existing documents, interview and focused group discussions with clinicians and hospital officials. We used real costs instead of charges for all cost inputs. We used direct allocation method for overhead/indirect cost allocation. In this allocation approach, all indirect costs (costs occurred outside the MRI center) were directly distributed on MRI services based on the time for each procedure. All calculations were done via Microsoft Excel 2007. Costing steps were carried out as below:

Activity center (AC) identification: Activity center is the place in which a set of related tasks are carried out in the form of main activity. The definition of these centers has great importance in ABC. Routinely, departments of a hospital can be classified into three different ACs: overhead, intermediate and final activity center. The overhead ACs provide supportive services for intermediate and final service departments. Management and administrative, medical records and statistics, and facility management are examples of overhead ACs. Intermediate ACs provide services that are supportive to final ACs. Laboratory, pharmacy, laundry and diagnostic imaging wards are considered as intermediate ACs. Final $\mathrm{AC}$ is the point of direct contact with patients. Inpatient wards are examples of final ACs. These departments give final service to patients. Although in routine costing studies, the diagnostic centers were considered as intermediate ACs, in this study, we considered the MRI center as the final AC where cost objects (services) were delivered to the patients. Based on resource consumption, two different types of costs are identifiable; direct costs (are generated within MRI center) that are directly attributable to MRI services and indirect costs (generat- 
ed outside MRI center) that are allocated from overhead departments.

Cost allocation of overhead ACs: In order to calculate total direct cost of each overhead AC, all cost elements, including staff, consumables, depreciation of equipment and buildings, contract and municipal facilities (water, electricity, telephone and gas) were involved. Straight line method (in which the purchasing price subtracted from the salvage value divided by the useful lifetime (years) of the asset can be reasonably expected) was adopted for depreciation cost estimation. Because of the uncertainty respect to equipment's life time, two scenarios were developed based on minimum and maximum useful lifetime of buildings and medical equipments (Table 1). According to the direct allocation method, the total cost of each AC was allocated to the final ACs based on appropriate cost drivers. For example, we used the "number of personnel" to allocate management, supplies, financial accounting, depot, and information technology (IT) departments total cost. "Time", "workload", "square meter", and "the number of medical devices" were used for cost allocation of other ACs.

Unit cost calculation of MRI services: Trough a mul- tiple approach, including interviews, medical records examination, hospital information system inquiries and focused group discussions with experts, all procedures were defined in detail. Then necessary resources (personnel time, disposables, and energy) for each procedure were measured in natural units and valued based on domestic prices. Cost elements for direct MRI services involve personnel expenses, consumable materials, energy, depreciation cost of building, and medical devices. Unitcost was calculated in two steps. In the first step, we identified resources used by each service, and then relevant resources were directly dedicated to each service. In the second step, total cost of resources that was commonly consumed by a group of services was distributed using workflow time of each imaging procedure. At the end of costing approach, we calculated a real unit cost relevant to 34 MRI services.

Comparison of calculated unit-cost with official approved tariffs: to clarify controversies among healthcare providers and insurance companies, all calculated unit costs were compared with official tariffs for public sectors (documented in tariff book). The official tariffs are annually announced by the Iranian Ministry of Health.

Table 1. Total Annual Cost in Terms of Cost Elements within the MRI Activity Center, Fiscal Year 2011 (USD)

\begin{tabular}{|c|c|c|c|}
\hline \multirow[t]{2}{*}{ The Type of Cost Element } & \multirow[t]{2}{*}{ Variable Costs } & \multicolumn{2}{|c|}{ Capital Costs } \\
\hline & & $\begin{array}{l}\text { The Minimum Useful Life of } \\
\text { Capitals }\end{array}$ & $\begin{array}{l}\text { The Maximum Useful Life of } \\
\text { Capitals }\end{array}$ \\
\hline Labor cost & 146.798 & & \\
\hline \multicolumn{4}{|l|}{ Consumables } \\
\hline Nonmedical & 1.737 & & \\
\hline Medical & 146.638 & & \\
\hline Depreciation cost of building & & 100.833 & 15.125 \\
\hline \multicolumn{4}{|l|}{ Depreciation cost of equipment } \\
\hline Nonmedical & & 2.477 & 1.223 \\
\hline Medical & & 132.920 & 88.493 \\
\hline \multicolumn{4}{|l|}{ Municipal services } \\
\hline Water & 35 & & \\
\hline Electricity & 372 & & \\
\hline Gas & 92 & & \\
\hline Telephone & 231 & & \\
\hline Sum & 295.904 & 236.200 & 104.842 \\
\hline $\begin{array}{l}\text { Total costs of MRI center (variable + } \\
\text { capital) }\end{array}$ & & 532.104 & 400.747 \\
\hline
\end{tabular}




\section{Results}

Results related to the cost of supportive ACs and the unit costs of 33 selected services are presented briefly. Among these ACs, the AC of cleaning and public services, and the cost of energy had the maximum total annual cost. In contrast, the AC of financial accounting and the AC of IT had the minimum annual cost. The labor cost accounts for the most significant share (more than $80 \%$ ) of the annual cost of supportive ACs.

Table 1 shows the total annual cost within the MRI AC in terms of variable costs (labor, non-medical consumables and energy cost) and capital costs (the depreciation of the buildings and non-medical equipment). According to the first and second scenarios, variable costs of this AC account for more than 55 and 73 percent of the total cost, respectively.

Table 2 divides cost categories into two direct and indirect costs. Direct costs constitute the most of the costs within the MRI sector. Among direct costs, the maximum share was related to labor and consumables costs. Among indirect costs, the depreciation cost of building had the maximum share. Total annual cost of the MRI AC included the costs within the AC and the costs that were allocated from other supportive ACs to the MRI AC. Table 3 shows the total cost of the MRI AC in the fiscal year. Almost 90 percent of the costs came from within the MRI $\mathrm{AC}$, and the remaining 10 percent came from overhead and intermediate ACs.

The unit costs of 33 selected services are presented in Table 4 . The variable cost elements are divided into medical consumables, labor, depreciation of medical equipment, nonmedical consumables, depreciation of nonmedical equipment and buildings, cost allocated from other departments, and energy costs. Among various services of MRI, arm-forearm-hand CS, femur-leg-foot CS, and shoulder-elbow-wrist CS had the maximum cost and brain CS had the minimum cost.

The last part of the findings compares the cost of MRI services with existing tariffs. The last columns in Table 4 show the official approved tariffs of MRI services in 2011 and the differences between tariffs and real costs. Existing tariffs for more than half of MRI services were above the calculated costs.

Table 2. The Share of Direct/Indirect Costs Within the MRI Activity Center in Fiscal Year 2011 a,b,c

\begin{tabular}{lcc}
\hline Types of Costs & Scenario 1 $\mathbf{b}$ & Scenario 2 \\
\hline Direct & 80.11 & 95.3 \\
\hline Labor cost & 27.85 & 36.63 \\
\hline Medical consumables & 27.55 & 36.59 \\
\hline Depreciated cost of Medical equipment & 24.98 & 22.08 \\
\hline Indirect & 19.89 & 4.7 \\
\hline Non-medical consumables & 0.32 & 0.43 \\
\hline Depreciation cost of non-medical equipment & 0.34 & 0.3 \\
\hline Depreciation cost of building & 18.94 & 3.77 \\
\hline
\end{tabular}

a Data ate presented as \%.

b Based on minimum useful life.

c Based on maximum useful life.

Table 3. Total Annual Cost of the MRI Activity Center in Fiscal Year 2011(USD)

\begin{tabular}{lcc}
\hline Costs & Scenario 1 & Scenario 2 \\
\hline Within the activity center & $532104(91.5)$ & $400746(89.5)$ \\
Allocated from other centers & $49966(8.5)$ & $46692(10.5)$ \\
Total cost & $582070(100)$ & $447456(100)$ \\
\hline
\end{tabular}


Bayati M et al.

Table 4. Unit Cost in Terms of Cost Elements for 33 MRI Services in Fiscal Year 2011 (USD) ${ }^{\text {a,b }}$

\begin{tabular}{|c|c|c|c|c|c|c|c|c|c|c|c|c|c|c|}
\hline 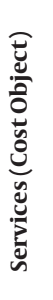 & 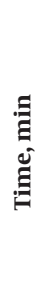 & 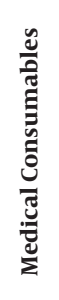 & 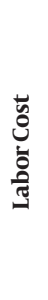 & 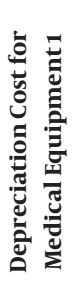 & 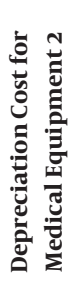 & 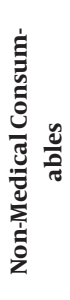 & 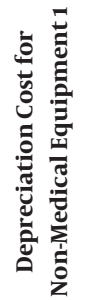 & 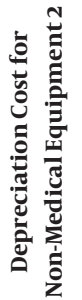 & 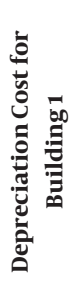 & 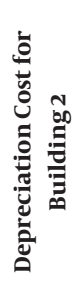 & 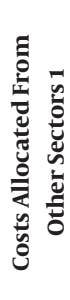 & 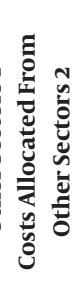 & 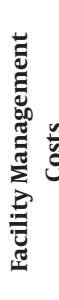 & \\
\hline
\end{tabular}

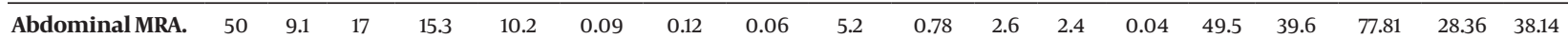
s.c.

\begin{tabular}{|c|c|c|c|c|c|c|c|c|c|c|c|c|c|c|c|c|c|c|}
\hline $\begin{array}{l}\text { Abdominal MRI. } \\
\text { c. s. }\end{array}$ & 60 & 24.6 & 20.4 & 18.4 & 12.2 & 0.09 & 0.12 & 0.06 & 5.2 & 0.78 & 2.6 & 2.4 & 0.04 & 71.5 & 60.5 & 87.33 & 15.88 & 26.76 \\
\hline $\begin{array}{l}\text { Abdominal } \\
\text { MRI.c. }\end{array}$ & 45 & 17.7 & 15.3 & 13.8 & 9.2 & 0.09 & 0.12 & 0.06 & 5.2 & 0.78 & 2.6 & 2.4 & 0.04 & 54.8 & 45.5 & 52.44 & -2.41 & 6.87 \\
\hline $\begin{array}{l}\text { Arm-Forearm } \\
\text {-Hand.c. s. }\end{array}$ & 120 & 41.5 & 40.7 & 36.9 & 24.5 & 0.09 & 0.12 & 0.06 & 5.2 & 0.78 & 2.6 & 2.4 & 0.04 & 127 & 110.07 & 87.33 & -39.82 & -22.74 \\
\hline Brain. c. & 20 & 6.8 & 6.8 & 6 & 4 & 0.09 & 0.12 & 0.06 & 5.2 & 0.78 & 2.6 & 2.4 & 0.04 & 27.7 & 20.97 & 52.44 & 24.79 & 31.47 \\
\hline Brain.s. & 8 & 4.6 & 2.7 & 2.4 & 1.6 & 0.09 & 0.12 & 0.06 & 5.2 & 0.78 & 2.6 & 2.4 & 0.04 & 17.7 & 12.27 & 61.25 & 43.5 & 48.98 \\
\hline Brain.c.s. & 28 & 11.4 & 9.5 & 8.6 & 5.7 & 0.09 & 0.12 & 0.06 & 5.2 & 0.78 & 2.6 & 2.4 & 0.04 & 37.5 & 29.97 & 87.33 & 49.78 & 57.36 \\
\hline Cervical.c.s. & 15 & 7 & 5.1 & 4.6 & 3.1 & 0.09 & 0.12 & 0.06 & 5.2 & 0.78 & 2.6 & 2.4 & 0.04 & 24.6 & 18.37 & 87.33 & 62.68 & 68.96 \\
\hline Cervical MRA. c. s. & 20 & 5.4 & 6.8 & 6.1 & 4.1 & 0.09 & 0.12 & 0.06 & 5.2 & 0.78 & 2.6 & 2.4 & 0.04 & 26.3 & 19.64 & 77.81 & 51.46 & 58.17 \\
\hline Cervical.s. & 30 & 7.5 & 10.2 & 9.2 & 6.1 & 0.09 & 0.12 & 0.06 & 5.2 & 0.78 & 2.6 & 2.4 & 0.04 & 34.9 & 27.2 & 52.44 & 17.5 & 25.24 \\
\hline Cervical.c. & 10 & 6.5 & 3.4 & 3.1 & 2 & 0.09 & 0.12 & 0.06 & 5.2 & 0.78 & 2.6 & 2.4 & 0.04 & 21 & 15.4 & 61.25 & 40.17 & 45.85 \\
\hline $\begin{array}{l}\text { Femur-Leg-Foot. } \\
\text { c. s. }\end{array}$ & 120 & 41.5 & 40.7 & 36.9 & 24.6 & 0.09 & 0.12 & 0.06 & 5.2 & 0.78 & 2.6 & 2.4 & 0.04 & 127 & 110.17 & 87.33 & -39.82 & -22.84 \\
\hline Femur-Leg-Foot. s. & 60 & 26.1 & 20.8 & 18.4 & 12.3 & 0.09 & 0.12 & 0.06 & 5.2 & 0.78 & 2.6 & 2.4 & 0.04 & 72.9 & 62.13 & 52.44 & -20.51 & -9.69 \\
\hline Hip-Knee-Ankle. c. & 90 & 17.3 & 30.6 & 27.7 & 18.4 & 0.09 & 0.12 & 0.06 & 5.2 & 0.78 & 2.6 & 2.4 & 0.04 & 83.6 & 69.69 & 61.25 & -22.35 & -8.44 \\
\hline $\begin{array}{l}\text { Hip-Knee-Ankle. } \\
\text { c. s. }\end{array}$ & 120 & 35.9 & 40.7 & 36.9 & 24.6 & 0.09 & 0.12 & 0.06 & 5.2 & 0.78 & 2.6 & 2.4 & 0.04 & 121.6 & 104.62 & 87.33 & -34.28 & -17.29 \\
\hline Hip-Knee-Ankle. s. & 60 & 20.5 & 20.4 & 18.4 & 12.3 & 0.09 & 0.12 & 0.06 & 5.2 & 0.78 & 2.6 & 2.4 & 0.04 & 67.4 & 56.58 & 52.44 & -14.96 & -4.14 \\
\hline Lumbosacral. s. c. & 17 & 7 & 5.8 & 5.2 & 3.5 & 0.09 & 0.12 & 0.06 & 5.2 & 0.78 & 2.6 & 2.4 & 0.04 & 26.06 & 19.66 & 87.33 & 61.27 & 67.67 \\
\hline Lumbosacral. c. & 12 & 3 & 4.1 & 3.7 & 2.4 & 0.09 & 0.12 & 0.06 & 5.2 & 0.78 & 2.6 & 2.4 & 0.04 & 18.8 & 12.92 & 61.25 & 42.45 & 48.33 \\
\hline Lumbosacral. s. & 12 & 4.4 & 4.1 & 3.7 & 2.4 & 0.09 & 0.12 & 0.06 & 5.2 & 0.78 & 2.6 & 2.4 & 0.04 & 20.27 & 14.39 & 52.44 & 32.17 & 38.05 \\
\hline MRS & 60 & 8 & 20.4 & 18.4 & 12.3 & 0.09 & 0.12 & 0.06 & 5.2 & 0.78 & 2.6 & 2.4 & 0.04 & 54.84 & 44.02 & 81.95 & 27.11 & 37.93 \\
\hline Common MRU & 30 & 6 & 10.2 & 9.2 & 6.1 & 0.09 & 0.12 & 0.06 & 5.2 & 0.78 & 2.6 & 2.4 & 0.04 & 33.47 & 25.74 & 73.66 & 40.19 & 47.92 \\
\hline Dynamic MRU & 30 & 6 & 10.2 & 9.2 & 6.1 & 0.09 & 0.12 & 0.06 & 5.2 & 0.78 & 2.6 & 2.4 & 0.04 & 33.47 & 25.74 & 87.33 & 53.86 & 61.59 \\
\hline $\begin{array}{l}\text { Bilateral MRM. } \\
\text { c. s. }\end{array}$ & 60 & 15.4 & 20.4 & 18.4 & 12.3 & 0.09 & 0.12 & 0.06 & 5.2 & 0.78 & 2.6 & 2.4 & 0.04 & 62.23 & 51.41 & 61.25 & -0.98 & 9.84 \\
\hline Pelvic. c. s. & 30 & 13.4 & 10.2 & 9.2 & 6.1 & 0.09 & 0.12 & 0.06 & 5.2 & 0.78 & 2.6 & 2.4 & 0.04 & 40.87 & 33.13 & 87.33 & 46.46 & 54.2 \\
\hline Pelvic. s. & 20 & 8.7 & 6.8 & 6.1 & 4.1 & 0.09 & 0.12 & 0.06 & 5.2 & 0.78 & 2.6 & 2.4 & 0.04 & 29.67 & 22.96 & 52.44 & 22.77 & 29.48 \\
\hline $\begin{array}{l}\text { Shoulder-Elbow- } \\
\text { Wrist.c. }\end{array}$ & 90 & 17.3 & 30.6 & 27.7 & 18.4 & 0.09 & 0.12 & 0.06 & 5.2 & 0.78 & 2.6 & 2.4 & 0.04 & 83.6 & 69.69 & 61.25 & -22.35 & -8.44 \\
\hline $\begin{array}{l}\text { Shoulder-Elbow- } \\
\text { Wrist.c. s. }\end{array}$ & 120 & 41.4 & 40.7 & 36.9 & 24.6 & 0.09 & 0.12 & 0.06 & 5.2 & 0.78 & 2.6 & 2.4 & 0.04 & 127.16 & 110.17 & 87.33 & -39.83 & -22.84 \\
\hline $\begin{array}{l}\text { Shoulder-Elbow- } \\
\text { Wrist. s. }\end{array}$ & 60 & 26.1 & 20.4 & 18.4 & 12.3 & 0.09 & 0.12 & 0.06 & 5.2 & 0.78 & 2.6 & 2.4 & 0.04 & 72.95 & 62.13 & 52.44 & -20.51 & -9.69 \\
\hline Thoracic MRA & 20 & 5.4 & 6.8 & 6.1 & 4.1 & 0.09 & 0.12 & 0.06 & 5.2 & 0.78 & 2.6 & 2.4 & 0.04 & 26.35 & 19.64 & 77.81 & 51.46 & 58.17 \\
\hline Thoracic. c.s. & 15 & 6.9 & 5.1 & 4.6 & 3.1 & 0.09 & 0.12 & 0.06 & 5.2 & 0.78 & 2.6 & 2.4 & 0.04 & 24.64 & 18.44 & 87.33 & 62.69 & 68.89 \\
\hline Thoracic.s. & 12 & 4.5 & 4.1 & 3.7 & 2.4 & 0.09 & 0.12 & 0.06 & 5.2 & 0.78 & 2.6 & 2.4 & 0.04 & 20.27 & 14.39 & 52.44 & 32.17 & 38.05 \\
\hline MRCP & 30 & 11.6 & 10.2 & 9.2 & 6.1 & 0.09 & 0.12 & 0.06 & 5.2 & 0.78 & 2.6 & 2.4 & 0.04 & 39.02 & 31.28 & 73.66 & 34.64 & 42.38 \\
\hline MRV & 30 & 7.2 & 6.8 & 6.1 & 4.1 & 0.09 & 0.12 & 0.06 & 5.2 & 0.78 & 2.6 & 2.4 & 0.04 & 28.2 & 21.49 & 77.81 & 49.61 & 56.32 \\
\hline
\end{tabular}

a 1 US Dollar was worth 1000 Iranian Tomans

b Abbreviations: $\mathrm{c}$ in lower case with contrast; c.s, with and without contrast; MRA, MR Angiography; MRU, MR Urography; MRM, MR Mammography; MRCP, MR Cholangiopancreatography; MRV, MR Venograph; s, without contrast. 


\section{Discussion}

The adjusted $\mathrm{ABC}$ method of the current study would be applicable to the same MRI centers in public and private hospitals. However, because of existing heterogeneity in structure and management of public hospitals, generalizability of results remains questionable. Cost analysis of administrative and supportive centers reveals that most of the annual cost of these departments is due to labor cost. This finding is in accordance with the findings of previous studies. Nasiripour et al. estimated that labor cost accounts for about 50 percent of total hospital cost (13). Another study by Hadian et al. reported the share of labor cost around 48 percent (14).

It is noteworthy that administrative and supportive departments of Shahid Faghihi hospital not only impose considerable expenditures on the total annual cost, but also have considerable impact on the total cost of other diagnostic and therapeutic sectors. Activity standardization and the optimal use of human resources seem to be efficient strategies for cost containment in public hospitals.

One of the main reasons for excessive capital cost in Shahid Faghihi hospital is depreciation cost of medical equipment, in particular the depreciation cost of MRI devices. This calls for more attention in calibrating and maintaining medical equipment in this area.

There are different findings reported for the share of direct and indirect costs in the recent literature. Nasiripour et al. stated an approximate 72 percent share for direct costs from total hospital costs (13). Saber Mahani et al. estimated a 97 percent share for direct costs (6). In the present study, the share of direct costs from MRI AC's total cost accounted for more than 90 percent of the total cost. The high ratio of direct cost in comparison with indirect cost indicates high efficiency of the MRI center and the optimal use of production capacity in service delivering.

Two important reasons for the observed differences among calculated unit costs were workflow time of imaging procedures and the amount of medical consumables. Since indirect costs and commonly used direct costs were allocated to cost objects (MRI services) based on workflow time, it is clear that the observed differences among unit costs resulted from differences among workflow (8 to 120 minutes).

Comparison of calculated unit costs with the approved tariffs showed that relevant for most services (more than 60 percent), unit costs were less than their tariffs. Furthermore, for some services, the cost was slightly more. Many studies in Iran have reported conflicting results. For example, Abbasi-Moghadam compared neurosurgery services with their tariffs and showed that the unit-cost was more than tariffs (15). Nasiripour et al. compared the unit-cost of laboratory services with tariffs and concluded that costs of services are relatively more than approved tariffs (13). Torabi et al. demonstrated that out of 35 calculated unit-cost of radiology services, the unit-cost of 32 services was more than the approved tariffs (16).
However, Mohammadi et al. showed that tariffs of dialysis services, are more than costs (17). This heterogeneity in results can be due to the costing method they used, lack of appropriate clinical and financial data and inducing some personal judgments.

Iranian public hospitals as a key provider of health-care have been buckling under many substantial problems. The primarily developed financial system of health organizations, particularly public hospitals might not be able to provide accurate, on time data required for managerial analyses. The gap between clinical and financial information system has caused complicated difficulties in real cost measurements. In such a competitive market without appropriate unit-cost data, all outsourcing contracts would result in failure. It is clear that public hospitals can make a great progress through upgrading their financial systems from hard copies to computerized information systems. We used a reliable and replicable method that can help hospitals measure their diagnostic service's real cost. Our study results show that the claim for excessive charges from health providers may not be relevant for all services. It is from the great importance that tariff setting processes should be done using validated acceptable costing methods.

The main limitation of the study was lack of appropriate and accurate data. As a result, in some cases the researchers had to estimate some variables.

\section{Acknowledgements}

We would like to thank the Health Policy Research Center (HPRC) of Shiraz University of Medical Sciences for financial supports. We are grateful of Shahid Faghihi Hospital Staff for participating in activity analysis interviews and data gathering processes.

\section{Authors' Contributions}

Mohsen Bayati and Alireza Mahboub Ahari managed activity analysis interviews and resource analysis for administrative departments. Mahin Gholipour and Abbas Badakhshan performed clinical procedure analysis and timing studies. Alireza Mahboub Ahari and Mohsen Bayati conducted cost analysis and unit-cost calculation. Alireza Mahboub Ahari and Mohsen Bayati prepared the financial part of the draft, and the clinical part was prepared by Mahin Gholipour. The draft was revisited by all authors for correction and finalization.

\section{Financial Disclosure}

All authors received grants based on their contribution to the project. The fund for this study has been provided by a public research institution. Nobody received other grants out of the project.

\section{Funding/Support}

Financial resource for the study has been provided by 
Health Policy Research Center (HPRC) of Shiraz University of Medical Sciences.

\section{References}

1. Kesteloot K, Lievens Y, van der Schueren E. Improved management of radiotherapy departments through accurate cost data. Radiother Oncol. 2000;55(3):251-62.

2. Ahari AM, Ghyassi FS, Yousefi M, Amjadi M, Mostafaie A. Green Light Photo Selective Vaporization of the Prostate vs. Transurethral Resection of Prostate for Benign Prostatic Hyperplasia. J Lasers Med Sci. 2011;2(4).

3. Grandlich C. Using Activity-Based Costing in Surgery. AORN J. 2004;79(1):189-92.

4. Yereli AN. Activity-based costing and its application in a Turkish university hospital. AORN J. 2009;89(3):573-6.

5. Federowicz MH, Grossman MN, Hayes BJ, Riggs J. A tutorial on activity-based costing of electronic health records. Qual Manag Health Care. 2010;19(1):86-9.

6. Saber Mahani A, Barouni M, Bahrami Mohammad A, Goodarzi Gholamreza SS, Ebrahimipour Z, Sanjaripour Z. Cost Price Estimation of Radiology Services in Shafa Hospital. Toloo-e-Behdasht. 2011;10(1):50-61.

7. Chan YC. Improving hospital cost accounting with activity-based costing. Health Care Manage Rev. 1993;18(1):71-7.

8. Lexa FJ, Mehta T, Seidmann A. Managerial accounting applications in radiology. J Am Coll Radiol. 2005;2(3):262-70.
9. Lievens Y, van den Bogaert W, Kesteloot K. Activity-based costing: a practical model for cost calculation in radiotherapy. Int J Radiat Oncol Biol Phys. 2003;57(2):522-35.

10. Waters H, Abdallah H, Santillan D. Application of activity-based costing (ABC) for a Peruvian NGO healthcare provider. Int J Health Plann Manage. 2001;16(1):3-18.

11. Kumar A. Towards the use of ontologies for activity-based costing in healthcare organizations. Stud Health Technol Inform. 2006;124:537-42.

12. Kuchta D, Zabek S. Activity-based costing for health care institutions.; 8th international conference on enterprise systems.; Thassos Island, Greece. 2011.

13. Nasiripour A, Tabibi J, Maleki M, Nourozi T. Computation Cost Price of clinical laboratories services in valiasr hospitals in Tehran in 1387 by using of ABC model. Hospital. 2010;8(3):5-17.

14. Hadian M, Mohammadzadeh A, Imani A, Golestani M. [Unit Cost Estimation of Hospital Services using Step-Down Cost Accounting Method]. Health Manag. 2009;12(37):39-48.

15. Abbasi Moghadam M. Unit Cost calculation of Neurosurgeries in Comparison with Official Tariffs. Sch Med J.1998;6:81-7.

16. Torabi A, Kheshavarz K, Najafpour J, Mohammadi E. Calculation of Cost Price of Services Delivered in Radiology Ward in Golestan Hospital through Activity Based Costing. Hospital. 2011;10(2):1-12.

17. Mohammadi Y, Bahrami M,, Baghestani E, Entezarian S, Ahmadi Tehrani G. Calculating the Cost Price of Dialysis in Shahid Sadoughi Hospital Using Activity Based Costing: Yazd. J Health Accounting. 2012;1(1):73-84. 